\title{
Measurement of Congestion in the Simultaneous Presence of Desirable and Undesirable Outputs
}

\author{
H. Zare-Haghighi, M. Rostamy-Malkhalifeh, and G. R. Jahanshahloo \\ Department of Mathematics, Science and Research Branch, Islamic Azad University, Tehran 1477893855, Iran \\ Correspondence should be addressed to M. Rostamy-Malkhalifeh; mohsen_rostamy@yahoo.com
}

Received 18 January 2014; Revised 15 March 2014; Accepted 15 March 2014; Published 15 April 2014

Academic Editor: Mohammad Khodabakhshi

Copyright (c) 2014 H. Zare-Haghighi et al. This is an open access article distributed under the Creative Commons Attribution License, which permits unrestricted use, distribution, and reproduction in any medium, provided the original work is properly cited.

\begin{abstract}
The concept of congestion, which is mainly applied in economics, refers to a situation where inputs are overinvested. Many studies have focused on congestion measurement by means of data envelopment analysis (DEA). However, most of the previous investigations only considered the framework of desirable outputs. In fact, firms in the real world unavoidably generate undesirable outputs (such as pollutants or wastes) along with desirable outputs. Therefore, a new scheme is required for measuring congestion in the simultaneous presence of both desirable and undesirable outputs. This paper develops a nonradial efficiency measure for including undesirable outputs into the environmental performance. Based on the proposed model, a new definition and a new approach are presented to deal with congestion in the simultaneous presence of desirable and undesirable outputs. Then, this paper uses the presented method to study the pollutants (waste gas emission and waste discharge) of 31 administrative regions of China. The finding indicates that 7 industries pay attention to the reduction of their pollutants accompanying improvement of their commercial targets. Consequently, they do not show congestion in any input.
\end{abstract}

\section{Introduction}

The concept of congestion, which is mainly applied in economics, refers to a situation where inputs are overinvested [1]. A typical example of congestion is the case where too many men in an underground coal mine may reduce the output of coal.

The topic of congestion was initially defined and extended by the essay of Fare and Svensson [2] in 1980. Afterwards, it was examined by Fare and Grosskopf [3] within the data envelopment analysis framework. They imposed the assumptions of weak and strong disposability on the production possibility set to identify the evidence of congestion. Besides, their approach suffers from some weaknesses in treating congestion [4]. In addition, a slacks-based measure was presented by Cooper et al. [5] that has some strong points compared to the previous method and can identify the congested inputs and the amount of congestion in each input. Moreover, Jahanshahloo and Khodabakhshi [6] developed an input relaxation model for improving outputs and, accordingly, calculated the input congestion based on the proposed model. Wei and Yan [7] estimated congestion by the ratio of technical efficiency to pure technical efficiency. However, their approach shows only existence or nonexistence of congestion and cannot provide a value for measuring the amount of congestion in each input.

Indeed, the investigations into congestion within the DEA framework have received considerable attention in the last few decades. Some of the other investigations in this field include Asgharian et al. [8], Flegg and Allen [9], Khodabakhshi [10], Sueyoshi and Sekitani [11], and Tone and Sahoo [12], to name a few.

According to Cooper et al. [1], the common understanding of congestion is that a decrease (increase) in one or more inputs results in an increase (decrease) in one or more outputs. From this viewpoint, all outputs are expected to rise. Outputs of this kind are called desirable outputs. However, an important issue is that, in the real world, undesirable outputs (such as pollutants or wastes) are unavoidably generated along with desirable outputs. Therefore, a new scheme is required for measuring congestion in the simultaneous presence of both desirable and undesirable outputs.

In recent years, many researchers have been trying to model undesirable outputs within the DEA framework. 
A common treatment of undesirable outputs is to regard them as inputs and apply the traditional DEA models. Some of the works in this area include Dyson et al. [13], Hailu and Veeman [14], Dyckhoff and Allen [15], and Sueyoshi and Goto [16]. Nevertheless, this routine causes two problems. First, the free disposability principle between inputs and bad outputs implies that a finite amount of inputs can produce an infinite amount of undesirable outputs, while this is physically impossible [17]. Second, the free disposability principle does not recognize the relation between desirable and undesirable outputs [18].

Seiford and Zhu [19] employed an alternative approach that first multiplies each undesirable output by -1 and then adds a big enough positive scalar to them in order to let all negative undesirable outputs be positive. Nevertheless, this approach is only valid under the variable returns to scale condition, and, furthermore, it does not reflect a rational production possibility set.

Scheel [20] inverted the undesirable output values and treated them as desirable. This nonlinear transformation may change the efficiency frontiers, though, and hence result in erroneous efficiency scores.

However, this subject was first methodically dealt with by Fare et al's publications $[17,21]$. They thought of undesirable outputs as outputs and tried to incorporate them into production possibility set under a new axiom. Thus, they employed the weak disposability assumption, which had been introduced by Shephard [22], between good and bad outputs. Later, the study was extended in this direction by scholars such as Fare et al. [23], Zhou et al. [24], Kuosmanen [25], and Kousmanen and Podinovski [18].

Although there are many papers in the DEA literature which discuss the theory and applications of congestion (see, e.g., $[1,4,7-12,26,27]$ among others), studying this subject in the presence of undesirable outputs is very young. In existing paper only, Wu et al. [28] have studied congestion measurement considering both desirable and undesirable outputs. However, they chose the method of Seiford and Zhu [19] to address undesirable outputs, and, moreover, they applied Wei and Yan approach [7] and determined only existence or nonexistence of congestion.

In this paper, we choose the Kuosmanen [25] technology to address the undesirable outputs. The reasons for choosing this technology have been clarified in Section 2. Employing the Kuosmanen technology, we present a nonradial efficiency measure that incorporates in both good and bad outputs. Then, following Cooper's idea for measuring congestion, a new definition and a new approach are presented to deal with congestion in the simultaneous presence of desirable and undesirable outputs.

The rest of this paper is arranged as follows. In Section 2, we review the two-model approach of Cooper et al. [5] for congestion measurement and the Kuosmanen [25] technology for addressing undesirable outputs. Section 3 provides an efficiency measure that incorporates in both good and bad outputs. Thereafter, we focus on congestion in the simultaneous presence of both desirable and undesirable outputs and offer a plain definition. Furthermore, an approach is proposed in order to deal with this type of congestion. In Section 4, the results of the presented models are supplied and interpreted, regarding an empirical application corresponding to 31 administrative regions of China. The summary of the study and directions for future researches are provided in Section 5.

\section{Preliminaries}

The assumption in this paper is that there are $n$ observed and comparable Decision Making Units (DMUs). The $j$ th DMU, $j \in\{1, \ldots, n\}$, is determined by the vector $\left(x_{j}, g_{j}, b_{j}\right)$, where $x_{j}=\left(x_{1 j}, x_{2 j}, \ldots, x_{m j}\right) \in R^{m}, x_{j} \geq 0, x_{j} \neq 0$, is the vector of inputs, $g_{j}=\left(g_{1 j}, g_{2 j}, \ldots, g_{s j}\right) \in R^{s}$, $g_{j} \geq 0, g_{j} \neq 0$, is the vector of desirable (good) outputs, and $b_{j}=\left(b_{1 j}, b_{2 j}, \ldots, b_{h j}\right) \in R^{h}, b_{j} \geq 0, b_{j} \neq 0$, is the vector of undesirable (bad) outputs. Next, Cooper's method for congestion evaluation [5] and the Kuosmanen technology [25] for addressing undesirable outputs are delineated.

2.1. Cooper's Method. Here, we review Cooper's approach for congestion evaluation, which considers only desirable outputs. This technique was first published by Cooper et al. [5] and was soon thereafter examined on real data and refined by Brockett et al. [26]. This approach, which is a slacks-based method, progresses in two stages. The first stage is directed to find a target point for each DMU via the output-oriented version of the BCC model. The output-oriented version has received more attention in congestion assessment because the input-oriented version may lead to wrong results in this area [1]. In the second stage, the outputs are fixed to those of the target point, and, afterwards, the maximum amount that can be added to the target's inputs is computed.

In Cooper's method, at first, the following well-known BCC model is solved:

$$
\begin{array}{ll}
\max & \varphi+\varepsilon\left(\sum_{i=1}^{m} s_{i}^{-}+\sum_{r=1}^{s} s_{r}^{+}\right) \\
\text {s.t. } \quad & \sum_{j=1}^{n} \lambda_{j} x_{i j}+s_{i}^{-}=x_{i k} \quad(i=1, \ldots, m), \\
& \sum_{j=1}^{n} \lambda_{j} g_{r j}-s_{r}^{+}=\varphi g_{r k} \quad(r=1, \ldots, s), \\
& \sum_{j=1}^{n} \lambda_{j}=1, \quad \lambda_{j} \geq 0 \quad(j=1, \ldots, n), \\
s_{i}^{-} \geq 0 \quad(i=1, \ldots, m), \\
s_{r}^{+} \geq 0 \quad(r=1, \ldots, s) .
\end{array}
$$

In Model $(1), \lambda_{j}(j=1, \ldots, n)$ is the $j$ th structural variable associated with the $j$ th DMU, and the $k$ index refers to the DMU under evaluation. Also, $s_{i}^{-}$and $s_{r}^{+}$are, respectively, the slack variables for the decrease in the $i$ th input and increase in the $r$ th output. In addition, $\varepsilon$ is a nonArchimedean element and applies only in theory in order to 
avoid rewriting the constraints of the model. Actually, the two-phase procedure is utilized to handle this element.

Let an optimal solution of Model (1) be $\left(\lambda^{*}, \varphi^{*}, s^{-*}, s^{+*}\right)$. Thus, the $\mathrm{DMU}_{k}$ is called strongly efficient if and only if $\varphi^{*}=$ $1, s^{-*}=0$, and $s^{+*}=0$ hold for every optimal solution of the model. Otherwise, the $\mathrm{DMU}_{k}$ can be projected on a strongly efficient target point $\left(\widehat{x}_{k}, \widehat{g}_{k}\right)$ by the following formulations:

$$
\begin{gathered}
\widehat{x}_{k}=\sum_{j=1}^{n} \lambda_{j}^{*} x_{j}=x_{k}-s^{-*}, \\
\widehat{g}_{k}=\sum_{j=1}^{n} \lambda_{j}^{*} g_{j}=\varphi^{*} g_{k}+s^{+*} .
\end{gathered}
$$

It is widely known that inefficiency is a necessary condition for the existence of congestion [1]. After recognizing whether $\mathrm{DMU}_{k}$ is inefficient, Brockett et al. [26] employed the target point (2) on the right-hand side of Model (3) as follows:

$$
\begin{array}{ll}
\max & \sum_{i=1}^{m} \delta_{i}^{+} \\
\text {s.t. } \quad & \sum_{j=1}^{n} \lambda_{j} x_{i j}-\delta_{i}^{+}=\widehat{x}_{i k} \quad(i=1, \ldots, m), \\
& \sum_{j=1}^{n} \lambda_{j} g_{r j}=\widehat{g}_{r k} \quad(r=1, \ldots, s), \\
& \sum_{j=1}^{n} \lambda_{j}=1, \lambda_{j} \geq 0 \quad(j=1, \ldots, n), \\
0 \leq \delta_{i}^{+} \leq s_{i}^{-*} \quad(i=1, \ldots, m) .
\end{array}
$$

This model calculates the maximum amount that can be added to the $i$ th input of the target point in order to remain in $T_{\mathrm{NEW}}$, which is obtained by assuming weak input disposability. In this way, the nonzero slack cannot be associated with any input. $T_{\mathrm{NEW}}$ is shown as follows:

$$
\begin{array}{r}
T_{\mathrm{NEW}}=\left\{(x, g) \mid x=\sum_{j=1}^{n} \lambda_{j} x_{j}, g \leq \sum_{j=1}^{n} \lambda_{j} g_{j},\right. \\
\left.\sum_{j=1}^{n} \lambda_{j}=1, \lambda_{j} \geq 0 ; j=1, \ldots, n\right\} .
\end{array}
$$

Eventually, Cooper's measure of the $i$ th input congestion, which is denoted here by $s_{i}^{c}$, is defined as

$$
s_{i}^{c}=s_{i}^{-*}-\delta_{i}^{+*} \quad(i=1, \ldots, m) .
$$

2.2. The Kuosmanen Technology. The production technology is characterized by the set $T=\{(x, g, b) \mid x$ can produce $(g, b)\}$. Consider the following principles which have been introduced in the DEA literature $[17,25]$ for incorporating undesirable factors into production technology.
(A1) Strong (free) disposability of inputs and good outputs. If $(x, g, b) \in T, 0 \leq g^{\prime} \leq g$, and $x^{\prime} \geq x$, then $\left(x^{\prime}, g^{\prime}, b\right) \in T$.

(A2) Weak disposability of good and bad outputs. If $(x, g, b) \in T, 0 \leq \theta \leq 1$, then $(x, \theta g, \theta b) \in T$.

(A3) $T$ is convex.

Axiom (A2) recognizes the relation between good and bad outputs because the pollutants and wastes can be reduced in proportion to the reduction of good outputs. The multiplier $\theta$ used in this axiom is pointed out as the abatement factor [25].

Kousmanen [25] applied $n$ different abatement factors to deal with axiom (A2). He argued that the correct minimum extrapolation technology necessitates $n$ distinctive abatement factors. Therefore, he employed distinctive abatement factors $\theta_{j}$ corresponding to each observed firm $j=1, \ldots, n$ and developed the following technology $\left(T_{K}\right)$ :

$$
\begin{aligned}
T_{K}=\left\{(x, g, b) \mid \sum_{j=1}^{n} \lambda_{j} x_{j} \leq x, \sum_{j=1}^{n} \theta_{j} \lambda_{j} g_{j} \geq g,\right. \\
\quad \sum_{j=1}^{n} \theta_{j} \lambda_{j} b_{j}=b, \sum_{j=1}^{n} \lambda_{j}=1, \lambda_{j} \geq 0, \\
\left.\quad(j=1, \ldots, n), 0 \leq \theta_{j} \leq 1,(j=1, \ldots, n)\right\} .
\end{aligned}
$$

Subsequently, Kuosmanen and Podinovski [18] proved that $T_{K}$ is indeed the only technology that contains all the observed firms and satisfies the minimum extrapolation principle of DEA under the mentioned axioms of (A1), (A2), and (A3).

In addition, it should be noted that $T_{K}$ is nonlinear, since $\theta_{j}$ is multiplied by $\lambda_{j}$. Nevertheless, Kuosmanen [25] stated that $T_{K}$ can be linearized as follows:

$$
\begin{gathered}
\lambda_{j}=\underbrace{\theta_{j} \lambda_{j}}_{\eta_{j}}+\underbrace{\left(1-\theta_{j}\right) \lambda_{j}}_{\mu_{j}} \quad(j=1, \ldots, n), \\
T_{K}=\left\{(x, g, b) \mid \sum_{j=1}^{n}\left(\eta_{j}+\mu_{j}\right) x_{j} \leq x, \sum_{j=1}^{n} \eta_{j} g_{j} \geq g,\right. \\
\sum_{j=1}^{n} \eta_{j} b_{j}=b, \sum_{j=1}^{n}\left(\eta_{j}+\mu_{j}\right)=1, \\
\left.\eta_{j} \geq 0, \mu_{j} \geq 0,(j=1, \ldots, n)\right\} .
\end{gathered}
$$

\section{The Proposed Models}

3.1. An Efficiency Measure. This section attempts to provide an efficiency measure that incorporates in both desirable and undesirable outputs. For this purpose, the Russell efficiency measure [29] of DEA is employed. This measure includes all 
the inefficiencies that the model can identify, as described by Pastor et al. [29]. Here, we have used the Kuosmanen technology to address the undesirable outputs. The proposed measure, which is denoted by $R M_{U}$, is as follows:

$$
\begin{gathered}
R M_{U} \\
=\min \frac{(1 /(m+h))\left(\sum_{i=1}^{m} \theta_{i}+\sum_{f=1}^{h} \gamma_{f}\right)}{(1 / s) \sum_{r=1}^{s} \varphi_{r}} \\
\text { s.t. } \quad\left(\theta_{1} x_{1 k}, \ldots, \theta_{m} x_{m k}, \varphi_{1} g_{1 k}, \ldots, \varphi_{s} g_{s k},\right. \\
\left.\gamma_{1} b_{1 k}, \ldots, \gamma_{h} b_{h k}\right)^{t} \in T_{K} \\
0 \leq \theta_{i} \leq 1 \quad(i=1, \ldots, m), \\
\varphi_{r} \geq 1 \quad(r=1, \ldots, s), \\
0 \leq \gamma_{f} \leq 1 \quad(f=1, \ldots, h) .
\end{gathered}
$$

In Model (8), the constraints $\theta_{i} \leq 1, \varphi_{r} \geq 1$, and $\gamma_{f} \leq 1$ are included in the model in order to see whether a DMU can be found to dominate $\mathrm{DMU}_{k}$. If this is not possible, that is, $R M_{U}=1, \mathrm{DMU}_{k}$ is environmentally efficient; otherwise, it is inefficient. Here, if $x_{i k}=0\left(b_{f k}=0\right)$, then the term $\theta_{i}\left(\gamma_{f}\right)$ is deleted from the objective function. Moreover, if $g_{r k}=0$, then it is replaced with a very small positive number which serves as a penalty. Using $T_{K}$, the outcome model is

$$
\begin{aligned}
& R M_{U} \\
& =\min \frac{(1 /(m+h))\left(\sum_{i=1}^{m} \theta_{i}+\sum_{f=1}^{h} \gamma_{f}\right)}{(1 / s) \sum_{r=1}^{s} \varphi_{r}} \\
& \text { s.t. } \sum_{j=1}^{n}\left(\eta_{j}+\mu_{j}\right) x_{i j} \leq \theta_{i} x_{i k} \quad(i=1, \ldots, m), \\
& \sum_{j=1}^{n} \eta_{j} g_{r j} \geq \varphi_{r} g_{r k} \quad(r=1, \ldots, s), \\
& \sum_{j=1}^{n} \eta_{j} b_{f j}=\gamma_{f} b_{f k} \quad(f=1, \ldots, h), \\
& \sum_{j=1}^{n}\left(\eta_{j}+\mu_{j}\right)=1, \quad \eta_{j} \geq 0, \\
& \mu_{j} \geq 0 \quad(j=1, \ldots, n), \\
& 0 \leq \theta_{i} \leq 1 \quad(i=1, \ldots, m), \\
& \varphi_{r} \geq 1 \quad(r=1, \ldots, s), \\
& 0 \leq \gamma_{f} \leq 1 \quad(f=1, \ldots, h) . \\
& (f=1, \ldots
\end{aligned}
$$

The $R M_{U}$ measure incorporates all of the inefficiencies that the model can identify. Simply, it can be verified that all of the constraints of the first, second, and third groups are binding on the optimality of Model (9). In the following theorem, we demonstrate that $R M_{U}$ lies between zero and unity.
Theorem 1. Consider the following:

$0<R M_{U} \leq 1$.

Proof. Since $\theta_{i}=1(\forall i), \varphi_{r}=1(\forall r), \gamma_{f}=1(\forall f) \mu_{j}=0$, $(\forall j), \eta_{j}=0,(\forall j \neq k)$, and $\eta_{k}=1$ is a feasible solution to Model (9) with objective function value $1, R M_{U} \leq 1$. Moreover, $\theta_{i} \geq 0(\forall i), \varphi_{r} \geq 1(\forall r)$, and $\gamma_{f} \geq 0(\forall f)$, and, therefore, $R M_{U} \geq 0$. Now, we only need to prove that $R M_{U} \neq 0$. Suppose that $R M_{U}=0$. This implies that $\theta_{i}=0(\forall i)$ and $\gamma_{f}=0(\forall f)$. Consequently, the undesirable constraints yield $\eta_{j}=0(\forall j)$, and hence the desirable constraints lead to $\varphi_{r} g_{r k} \leq 0(\forall r)$. At last, it is inferred that $g_{r k}=0(\forall r)$, while this is a contradiction. Consequently, $R M_{U} \neq 0$.

Note that Model (9) is a fractional programming problem; however, it can be transformed into an equivalent linear programming problem by using the Charnes-Cooper transformation. Holding $(1 / s) \sum_{r=1}^{s} \varphi_{r}=1 / t$ and multiplying each constraint by $t$, we thereafter let $t \eta_{j}=\eta_{j}^{\prime}, t \mu_{j}=\mu_{j}^{\prime}, t \theta_{i}=\theta_{i}^{\prime}$, $t \varphi_{r}=\varphi_{r}^{\prime}$, and $t \gamma_{f}=\gamma_{f}^{\prime}$, and thus the following linear problem is achieved:

$$
\begin{aligned}
& R M_{U} \\
& =\min \frac{1}{m+h}\left(\sum_{i=1}^{m} \theta_{i}^{\prime}+\sum_{f=1}^{h} \gamma_{f}^{\prime}\right) \\
& \text { s.t. } \quad \sum_{j=1}^{n}\left(\eta_{j}^{\prime}+\mu_{j}^{\prime}\right) x_{i j} \leq \theta_{i}^{\prime} x_{i k} \quad(i=1, \ldots, m) \text {, } \\
& \sum_{j=1}^{n} \eta_{j}^{\prime} g_{r j} \geq \varphi_{r}^{\prime} g_{r k} \quad(r=1, \ldots, s), \\
& \sum_{j=1}^{n} \eta_{j}^{\prime} b_{f j}=\gamma_{f}^{\prime} b_{f k} \quad(f=1, \ldots, h), \\
& \sum_{j=1}^{n}\left(\eta_{j}^{\prime}+\mu_{j}^{\prime}\right)=t \\
& \eta_{j}^{\prime} \geq 0, \mu_{j}^{\prime} \geq 0 \quad(j=1, \ldots, n), \\
& 0 \leq \theta_{i}^{\prime} \leq t \quad(i=1, \ldots, m), \\
& \varphi_{r}^{\prime} \geq t \quad(r=1, \ldots, s), \\
& 0 \leq \gamma_{f}^{\prime} \leq t \quad(f=1, \ldots, h), \\
& \sum_{r=1}^{s} \varphi_{r}^{\prime}=s, \quad t \geq 0
\end{aligned}
$$

As a result, we can easily obtain $R M_{U}$ via a linear problem for assessing the environmental performance of $\mathrm{DMU}_{k}$. Note that since $t>0$, the transformation is reversible. Let $\left(\eta^{\prime *}, \mu^{\prime *}, \theta^{\prime *}, \varphi^{\prime *}, \gamma^{\prime *}, t^{*}\right)$ be an optimal solution of Model (10); consequently, $\left(\eta^{*}=\eta^{\prime *} / t^{*}, \mu^{*}=\mu^{\prime *} / t^{*}, \theta^{*}=\right.$ $\left.\theta^{\prime *} / t^{*}, \varphi^{*}=\varphi^{\prime *} / t^{*}, \gamma^{*}=\gamma^{\prime *} / t^{*}\right)$ is an optimal solution of Model (9). 
The output-oriented version of the proposed measure can be defined by ignoring the reduction of inputs, that is, by omitting $\theta_{i}$, in the objective function of Model (9). Subsequently, the efficiency score $R M_{U}(O)$ can be achieved as follows:

$$
R M_{U}(O)
$$

$$
\begin{aligned}
=\min & \frac{(1 / h) \sum_{f=1}^{h} \gamma_{f}}{(1 / s) \sum_{r=1}^{s} \varphi_{r}} \\
\text { s.t. } & \sum_{j=1}^{n}\left(\eta_{j}+\mu_{j}\right) x_{i j} \leq x_{i k} \quad(i=1, \ldots, m), \\
& \sum_{j=1}^{n} \eta_{j} g_{r j} \geq \varphi_{r} g_{r k} \quad(r=1, \ldots, s), \\
\sum_{j=1}^{n} \eta_{j} b_{f j}=\gamma_{f} b_{f k} \quad(f=1, \ldots, h), & \\
\sum_{j=1}^{n}\left(\eta_{j}+\mu_{j}\right)=1, & (j=1, \ldots, n), \\
\eta_{j} \geq 0, \mu_{j} \geq 0 \quad & (r=1, \ldots, s), \\
\varphi_{r} \geq 1 \quad & (f=1, \ldots, h) .
\end{aligned}
$$

In a similar way, as described above, the equivalent linear program of the output-oriented Model (11) can be obtained as follows:

$$
\begin{aligned}
R M_{U}(O) & \\
=\min & \frac{1}{h} \sum_{f=1}^{h} \gamma_{f}^{\prime} \\
\text { s.t. } & \sum_{j=1}^{n}\left(\eta_{j}^{\prime}+\mu_{j}^{\prime}\right) x_{i j} \leq t x_{i k} \quad(i=1, \ldots, m), \\
& \sum_{j=1}^{n} \eta_{j}^{\prime} g_{r j} \geq \varphi_{r}^{\prime} g_{r k} \quad(r=1, \ldots, s), \\
& \sum_{j=1}^{n} \eta_{j}^{\prime} b_{f j}=\gamma_{f}^{\prime} b_{f k} \quad(f=1, \ldots, h), \\
& \sum_{j=1}^{n}\left(\eta_{j}^{\prime}+\mu_{j}^{\prime}\right)=t,
\end{aligned}
$$

$$
\begin{aligned}
& \eta_{j}^{\prime} \geq 0, \mu_{j}^{\prime} \geq 0 \quad(j=1, \ldots, n),(r=1, \ldots, s), \\
& \varphi_{r}^{\prime} \geq t \quad(f=1, \ldots, h), \\
& 0 \leq \gamma_{f}^{\prime} \leq t \quad(t \geq 0 .
\end{aligned}
$$

3.2. Congestion in the Simultaneous Presence of Desirable and Undesirable Outputs. As noted earlier, in traditional congestion, only desirable outputs are considered. Nevertheless, in the real world, undesirable outputs (such as pollutants or wastes) are unavoidably generated along with desirable outputs. In this subsection, we attempt to develop a new scheme for measuring congestion in the simultaneous presence of both desirable and undesirable outputs. The definition we present is as follows.

Definition 2. Congestion occurs in the performance of $\mathrm{DMU}_{k}=\left(x_{k}, g_{k}, b_{k}\right)$ whenever a reduction in one or more inputs can increase one or more desirable outputs and decrease one or more undesirable outputs without worsening any other input, desirable output, or undesirable output. In contrast, whenever an increase in one or more inputs can decrease one or more desirable outputs and increase one or more undesirable outputs without improving any other input, desirable output, or undesirable output.

Now we have tried to identify this type of congestion and determine its sources and amounts. For this purpose, first, the output-oriented version of the proposed measure is employed. This model determines the maximally possible amount of desirable outputs and the minimally possible amount of undesirable outputs that can be acquired by $\mathrm{DMU}_{k}$.

In fact, Model (11) recognizes whether $\mathrm{DMU}_{k}$ could achieve more desirable outputs and fewer undesirable outputs. If this is not possible, that is, if $R M_{U}(O)=1$, then congestion does not prevail at $\mathrm{DMU}_{k}$. Otherwise, congestion may be present in the performance of $\mathrm{DMU}_{k}$. Therefore, to capture the input congestion and identify its sources and amounts, Model (13) is employed as follows:

$$
\begin{array}{ll}
\min & \sum_{i=1}^{m} s_{i}^{c} \\
\text { s.t. } & \sum_{j=1}^{n}\left(\eta_{j}+\mu_{j}\right) x_{i j}=x_{i k}-s_{i}^{c} \quad(i=1, \ldots, m), \\
& \sum_{j=1}^{n} \eta_{j} g_{r j} \geq \varphi_{r}^{*} g_{r k} \quad(r=1, \ldots, s), \\
& \sum_{j=1}^{n} \eta_{j} b_{f j}=\gamma_{f}^{*} b_{f k} \quad(f=1, \ldots, h),
\end{array}
$$


TABLE 1: Data set of industry of China in 2010.

\begin{tabular}{|c|c|c|c|c|c|c|}
\hline District & $\mathrm{DMU}$ & $\begin{array}{l}\text { Input1 } \\
\text { TIFA }\end{array}$ & $\begin{array}{l}\text { Input2 } \\
\text { EC }\end{array}$ & $\begin{array}{l}\text { Desirable output } \\
\text { GIOV }\end{array}$ & $\begin{array}{c}\text { Undesirable outl } \\
\text { TWGE }\end{array}$ & $\begin{array}{c}\text { Undesirable out } 2 \\
\text { TWWD }\end{array}$ \\
\hline Anhui & D1 & $9,121.829$ & 1077.91 & 18,732 & 17,849 & 70,971 \\
\hline Beijing & D2 & $4,554.356$ & 809.9 & $13,699.84$ & 4,750 & 8,198 \\
\hline Chongqing & D3 & $5,049.258$ & 626.44 & $9,143.55$ & 10,943 & 45,180 \\
\hline Fujian & D4 & $6,534.803$ & 1315.09 & $21,901.23$ & 13,507 & 124,168 \\
\hline Gansu & D5 & $2,274.305$ & 804.43 & $4,882.68$ & 6,252 & 15,352 \\
\hline Guangdong & D6 & $11,903.36$ & 4060.13 & $85,824.64$ & 24,092 & 187,031 \\
\hline Guangxi & D7 & $5,166.135$ & 993.24 & $9,644.13$ & 14,520 & 165,211 \\
\hline Guizhou & D8 & $2,483.012$ & 835.38 & $4,206.37$ & 10,192 & 14,130 \\
\hline Hainan & D9 & 903.8264 & 159.02 & $1,381.25$ & 1,360 & 5,782 \\
\hline Hebei & D10 & $11,737.07$ & 2691.52 & $31,143.29$ & 56,324 & 114,232 \\
\hline Heilongjiang & D11 & $5,019.085$ & 747.84 & $9,535.15$ & 10,111 & 38,921 \\
\hline Henan & $\mathrm{D} 12$ & $12,868.24$ & 2353.96 & $34,995.53$ & 22,709 & 150,406 \\
\hline Hubei & D13 & $7,276.638$ & 1330.44 & $21,623.12$ & 13,865 & 94,593 \\
\hline Hunan & D14 & $7,374.157$ & 1171.91 & $19,008.83$ & 14,673 & 95,605 \\
\hline Inner Mongolia & D15 & $6,831.416$ & 1536.83 & $13,406.11$ & 27,488 & 39,536 \\
\hline Jiangsu & D16 & $18,977.92$ & 3864.37 & $92,056.48$ & 31,213 & 263,760 \\
\hline Jiangxi & D17 & $6,696.149$ & 700.51 & $13,883.06$ & 9,812 & 72,526 \\
\hline Jilin & D18 & $6,313.748$ & 576.98 & $13,098.35$ & 8.240 & 38,656 \\
\hline Liaoning & D19 & $12,480.94$ & 1715.26 & $36,219.42$ & 26,955 & 71,521 \\
\hline Ningxia & D20 & $1,193.702$ & 546.77 & $1,924.39$ & 16,324 & 21,977 \\
\hline Qinghai & D21 & 789.5051 & 465.18 & $1,481.99$ & 3,952 & 9,031 \\
\hline Shaanxi & D22 & $5,462.784$ & 859.22 & $11,199.84$ & 13,510 & 45,487 \\
\hline Shandong & D23 & $17,664.34$ & 3298.46 & $83,851.4$ & 43,837 & 208,257 \\
\hline Shanghai & D24 & $4,252.32$ & 1295.87 & $30,114.41$ & 12,969 & 36,696 \\
\hline Shanxi & D25 & $4,702.091$ & 1460 & $12,471.33$ & 35,190 & 49,881 \\
\hline Sichuan & D26 & $9,790.274$ & 1549.03 & $23,147.38$ & 20,107 & 93,444 \\
\hline Tianjin & D27 & $4,571.888$ & 645.74 & $16,751.82$ & 7,686 & 19,680 \\
\hline Tibet & D28 & 306.567 & 20.41 & 62.22 & 16 & 736 \\
\hline Xinjiang & D29 & $2,749.838$ & 661.96 & $5,341.9$ & 9,310 & 25,413 \\
\hline Yunnan & D30 & $4,024.972$ & 1004.07 & $6,464.63$ & 10,978 & 30,926 \\
\hline Zhejiang & D31 & $10,246.41$ & 2820.93 & $51,394.2$ & 20,434 & 217,426 \\
\hline
\end{tabular}

$$
\begin{gathered}
\sum_{j=1}^{n}\left(\eta_{j}+\mu_{j}\right)=1 \\
\eta_{j} \geq 0, \quad \mu_{j} \geq 0 \quad(j=1, \ldots, n), \\
s_{i}^{c} \geq 0 \quad(i=1, \ldots, m) .
\end{gathered}
$$

Fixing the outputs on the obtained optimal amounts, Model (13) computes the minimum amount that can be reduced from the $i$ th input of $\mathrm{DMU}_{k}$ in order to acquire these optimal amounts of outputs and also reach $T_{K_{\mathrm{NEW}}}$.

$T_{K_{\mathrm{NEW}}}$, which is gained by changing the input inequalities of $T_{K}$ to input equalities, is the NEW technology corresponding to Kuosmanen technology and is as follows:

$$
\begin{gathered}
T_{K_{\mathrm{NEW}}}=\left\{(x, g, b) \mid \sum_{j=1}^{n}\left(\eta_{j}+\mu_{j}\right) x_{j}=x, \sum_{j=1}^{n} \eta_{j} g_{j} \geq g,\right. \\
\sum_{j=1}^{n} \eta_{j} b_{j}=b, \sum_{j=1}^{n}\left(\eta_{j}+\mu_{j}\right)=1, \\
\left.\eta_{j} \geq 0, \mu_{j} \geq 0,(j=1, \ldots, n)\right\} .
\end{gathered}
$$

After solving Model (13), if $s_{i}^{c}>0$, then $s_{i}^{c}$ is the amount of congestion in the $i$ th input of $\mathrm{DMU}_{k}$. Otherwise, if $s_{i}^{c}=0$, congestion does not occur in the $i$ th input of $\mathrm{DMU}_{k}$.

\section{Numerical Example}

In this section, we apply the proposed method for assessing the congestion in 31 administrative regions of China. See the data set in Table 1 which is adopted form Wu et al's paper [28]. These data have two inputs: the total investment in fixed assets of industry (TIFA) and the electricity consumption by industry (EC), one desirable output: the gross industrial output value (GIOV), and two undesirable outputs: the total volume of industrial waste gas emission (TWGE) and the total volume of waste water discharge (TWWD). For ease of comparison, we have named the industries D1 to D31, which are depicted in the second column of Table 1.

We utilized the general algebraic modeling system (GAMS) software for the calculations. Table 2 displays the results of the presented models. The first column shows the results of the proposed measure which is computed by Model (10). D2, D6, D16, D23, D24, D27, and D28 are identified as the environmentally efficient industries and attain $R M_{U}=1$. Thus, we can conclude that these 7 industries pay attention to 
TABLE 2: Results of the proposed models.

\begin{tabular}{|c|c|c|c|c|c|}
\hline District & DMU & $\mathrm{RM}_{U}$ & $\mathrm{RM}_{U}(\mathrm{O})$ & $s_{1}^{c}$ & $s_{2}^{c}$ \\
\hline Anhui & D1 & 0.455 & 0.317 & 4054.732 & 41.241 \\
\hline Beijing & D2 & 1 & 1 & 0 & 0 \\
\hline Chongqing & D3 & 0.380 & 0.205 & 1481.994 & 0 \\
\hline Fujian & D4 & 0.526 & 0.372 & 1144.784 & 135.603 \\
\hline Gansu & D5 & 0.331 & 0.231 & 0 & 418.298 \\
\hline Guangdong & D6 & 1 & 1 & 0 & 0 \\
\hline Guangxi & D7 & 0.262 & 0.133 & 611.779 & 183.340 \\
\hline Guizhou & D8 & 0.257 & 0.161 & 0 & 410.458 \\
\hline Hainan & D9 & 0.375 & 0.248 & 0 & 27.604 \\
\hline Hebei & D10 & 0.364 & 0.290 & 7343.447 & 1344.598 \\
\hline Heilongjiang & D11 & 0.386 & 0.237 & 798.638 & 0 \\
\hline Hainan & D12 & 0.495 & 0.433 & 6144.005 & 584.392 \\
\hline Hubei & D13 & 0.517 & 0.395 & 1914.956 & 163.486 \\
\hline Hunan & D14 & 0.467 & 0.322 & 2278.853 & 122.766 \\
\hline $\begin{array}{l}\text { Inner } \\
\text { Mongolia }\end{array}$ & D15 & 0.319 & 0.186 & 2277.060 & 726.930 \\
\hline Jiangsu & D16 & 1 & 1 & 0 & 0 \\
\hline Jiangxi & D17 & 0.505 & 0.360 & 2412.607 & 0 \\
\hline Jilin & D18 & 0.604 & 0.516 & 2487.404 & 0 \\
\hline Liaoning & D19 & 0.652 & 0.635 & 7390.180 & 116.468 \\
\hline Ningxia & D20 & 0.150 & 0.047 & 0 & 361.478 \\
\hline Qinghai & D21 & 0.229 & 0.114 & 0 & 355.012 \\
\hline Shaanxi & D22 & 0.381 & 0.217 & 908.428 & 49.320 \\
\hline Shandong & D23 & 1 & 1 & 0 & 0 \\
\hline Shanghai & D24 & 1 & 1 & 0 & 0 \\
\hline Shanxi & D25 & 0.300 & 0.136 & 147.735 & 650.100 \\
\hline Sichuan & D26 & 0.444 & 0.350 & 4273.281 & 313.386 \\
\hline Tianjin & $\mathrm{D} 27$ & 1 & 1 & 0 & 0 \\
\hline Tibet & D28 & 1 & 1 & 0 & 0 \\
\hline Xinjiang & D29 & 0.287 & 0.162 & 0 & 187.446 \\
\hline Yunnan & D30 & 0.255 & 0.165 & 0 & 292.561 \\
\hline Zhejiang & D31 & 0.697 & 0.597 & 1851.267 & 312.372 \\
\hline
\end{tabular}

the reduction of their pollutants accompanying improvement of their commercial targets.

The second column depicts the results of the outputoriented measure which is computed by Model (12). It should be noticed that some industries (such as D7, D8, D15, D20, $\mathrm{D} 21, \mathrm{D} 25, \mathrm{D} 29$, and D30) obtain a very low $R M_{U}(O)$. As a result, these industries should be seriously concerned about their outputs. Especially, they should pay more attention to the reduction of their pollutants and wastes.

The amount of congestion in each input, which is calculated by Model (13), is presented in the two last columns of Table 2. The 7 above-mentioned industries, which performed efficiently, do not show congestion in any input. The other industries evidence congestion in one or both of their inputs. For instance, congestion exists in the second input of D5. Therefore, D5 can reduce its electricity consumption in amounts of $s_{2}^{c}=418.298$ and, accordingly, its desirable output increases and its undesirable outputs decrease. Or D25 shows congestion in both of its inputs. Therefore, it can reduce its investment in amounts of $s_{1}^{c}=147.735$ and its electricity consumption in amounts of $s_{2}^{c}=650.100$ and, accordingly, its desirable output increases and its undesirable outputs decrease.

\section{Summary and Conclusion}

The concept of congestion, which is mainly applied in the economics, points out a situation where inputs are overinvested. Many researchers have studied this subject using data envelopment analysis (DEA). However, most of the previous investigations only considered the framework of desirable outputs (see, e.g., $[6-8,10-12])$. In fact, firms in the real world unavoidably generate undesirable outputs (like pollutants or wastes) along with desirable outputs. Therefore, a new scheme is required for measuring congestion in the simultaneous presence of both desirable and undesirable outputs.

In this paper, we briefly introduced the Kuosmanen [25] technology which is available in the DEA literature for modeling environmental performance under the weak disposability assumption of desirable and undesirable outputs.

Then, we attempted to present a nonradial efficiency measure that incorporates in both desirable and undesirable outputs. Based on the proposed model, a new definition and a new approach are presented to deal with congestion in the simultaneous presence of desirable and undesirable outputs.

Afterwards, the presented method is applied to study the pollutants (waste gas emission and waste discharge) of 31 administrative regions of China. The finding of this paper shows that 7 industries pay attention to the reduction of their pollutants accompanying improvement of their commercial targets. Consequently, they do not show congestion in any input. The other industries evidence congestion in one or both of their inputs. Reducing the amount of congestion in each input, these industries can enhance their desirable output and decrease their undesirable outputs.

Possible future research is to study ranking of DMUs with undesirable outputs. Ranking efficient DMU is an important issue in DEA literature and many researchers have worked in this domain; see, for example, [30-38]. However, the research on this subject in the presence of undesirable outputs can be a future research agenda.

\section{Conflict of Interests}

The authors declare that there is no conflict of interests regarding the publication of this paper.

\section{References}

[1] W. W. Cooper, L. M. Seiford, and J. Zhu, "A unified additive model approach for evaluating inefficiency and congestion with associated measures in DEA," Socio-Economic Planning Sciences, vol. 34, no. 1, pp. 1-25, 2000.

[2] R. Fare and L. Svensson, "Congestion of production factors," Econometrica, vol. 48, no. 7, pp. 1745-1753, 1980. 
[3] R. Fare and S. Grosskopf, "Measuring congestion in production," Zeitschrift fur Nationalokonomie, vol. 43, pp. 257-271, 1993.

[4] W. W. Cooper, B. Gu, and S. Li, "Comparisons and evaluations of alternative approaches to the treatment of congestion in DEA," European Journal of Operational Research, vol. 132, no. 1, pp. 6274, 2001.

[5] W. W. Cooper, R. G. Thompson, and R. M. Thrall, "Introduction: extensions and new developments in DEA," Annals of Operations Research, vol. 66, pp. 3-45, 1996.

[6] G. R. Jahanshahloo and M. Khodabakhshi, "Suitable combination of inputs for improving outputs in DEA with determining input congestion considering textile industry of China," Applied Mathematics and Computation, vol. 151, no. 1, pp. 263-273, 2004.

[7] Q. L. Wei and H. Yan, "Congestion and returns to scale in data envelopment analysis," European Journal of Operational Research, vol. 153, no. 3, pp. 641-660, 2004.

[8] M. Asgharian, M. Khodabakhshi, and L. Neralic, "Congestion in stochastic data envelopment analysis: an input relaxation approach," International Journal of Statistics and System Science, vol. 5, pp. 84-106, 2010.

[9] A. T. Flegg and D. O. Allen, "Congestion in the Chinese automobile and textile industries revisited," Socio-Economic Planning Sciences, vol. 43, no. 3, pp. 177-191, 2009.

[10] M. Khodabakhshi, "A one-model approach based on relaxed combinations of inputs for evaluating input congestion in DEA," Journal of Computational and Applied Mathematics, vol. 230, no. 2, pp. 443-450, 2009.

[11] T. Sueyoshi and K. Sekitani, "DEA congestion and returns to scale under an occurrence of multiple optimal projections," European Journal of Operational Research, vol. 194, no. 2, pp. 592-607, 2009.

[12] K. Tone and B. K. Sahoo, "Degree of scale economies and congestion: a unified DEA approach," European Journal of Operational Research, vol. 158, no. 3, pp. 755-772, 2004.

[13] R. G. Dyson, R. Allen, A. S. Camanho, V. V. Podinovski, C. S. Sarrico, and E. A. Shale, "Pitfalls and protocols in DEA," European Journal of Operational Research, vol. 132, no. 2, pp. 245-259, 2001.

[14] A. Hailu and T. S. Veeman, "Non-parametric productivity analysis with undesirable outputs: an application to the Canadian pulp and paper industry," American Journal of Agricultural Economics, vol. 83, no. 3, pp. 605-616, 2001.

[15] H. Dyckhoff and K. Allen, "Measuring ecological efficiency with data envelopment analysis (DEA)," European Journal of Operational Research, vol. 132, no. 2, pp. 312-325, 2001.

[16] T. Sueyoshi and M. Goto, "Methodological comparison between two unified (operational and environmental) efficiency measurements for environmental assessment," European Journal of Operational Research, vol. 210, no. 3, pp. 684-693, 2011.

[17] R. Fare and S. Grosskopf, "Non-parametric productivity analysis with undesirable outputs," American Journal of Agricultural Economics, vol. 85, no. 4, pp. 1070-1074, 2003.

[18] T. Kuosmanen and V. Podinovski, "Weak disposability in nonparametric production analysis: reply to Fare and Grosskopf," American Journal of Agricultural Economics, vol. 91, no. 2, pp. 539-545, 2009.

[19] L. M. Seiford and J. Zhu, "Modeling undesirable factors in efficiency evaluation," European Journal of Operational Research, vol. 142, no. 1, pp. 16-20, 2002.
[20] H. Scheel, "Undesirable outputs in efficiency valuations," European Journal of Operational Research, vol. 132, no. 2, pp. 400410, 2001.

[21] R. Fare, S. Grosskopf, C. A. K. Lovell, and C. Pasurka, "Multilateral productivity comparisons when some outputs are undesirable: a nonparametric approach," The Review of Economics and Statistics, vol. 71, no. 1, pp. 90-98, 1989.

[22] R. W. Shephard, Indirect Production Functions, Verlag Anton Hain, Meisenheim am Glan, Germany, 1974, Mathematical Systems in Economics, No. 10.

[23] R. Fare, S. Grosskopf, D.-W. Noh, and W. Weber, "Characteristics of a polluting technology: theory and practice," Journal of Econometrics, vol. 126, no. 2, pp. 469-492, 2005.

[24] P. Zhou, K. L. Poh, and B. W. Ang, "A non-radial DEA approach to measuring environmental performance," European Journal of Operational Research, vol. 178, no. 1, pp. 1-9, 2007.

[25] T. Kuosmanen, "Weak disposability in nonparametric production analysis with undesirable outputs," American Journal of Agricultural Economics, vol. 87, no. 4, pp. 1077-1082, 2005.

[26] P. L. Brockett, W. W. Cooper, Y. Wang, and H. Shin, "Inefficiency and congestion in Chinese production before and after the 1978 economic reforms," Socio-Economic Planning Sciences, vol. 32, no. 1, pp. 1-20, 1998.

[27] M. Khoveyni, R. Eslami, M. Khodabakhshi, G. R. Jahanshahloo, and F. Hosseinzadeh Lotfi, "Recognizing strong and weak congestion slack based in data envelopment analysis," Computers and Industrial Engineering, vol. 64, pp. 731-738, 2013.

[28] J. Wu, Q. An, B. Xiong, and Y. Chen, "Congestion measurement for regional industries in China: a data envelopment analysis approach with undesirable outputs," Energy Policy, vol. 57, pp. 7-13, 2013.

[29] J. T. Pastor, J. L. Ruiz, and I. Sirvent, "Enhanced DEA Russell graph efficiency measure," European Journal of Operational Research, vol. 115, no. 3, pp. 596-607, 1999.

[30] F. Hosseinzadeh Lotfi, G. R. Jahanshahloo, M. Khodabakhshi, M. Rostamy-Malkhlifeh, Z. Moghaddas, and M. Vaez-Ghasemi, "A review of ranking models in data envelopment analysis," Journal of Applied Mathematics, vol. 2013, Article ID 492421, 20 pages, 2013.

[31] G. R. Jahanshahloo and M. Khodabakhshi, "Using input-output orientation model for determining most productive scale size in DEA," Applied Mathematics and Computation, vol. 146, no. 2-3, pp. 849-855, 2003.

[32] G. R. Jahanshahloo, M. Khodabakhshi, F. Hosseinzadeh Lotfi, and M. R. Moazami Goudarzi, "A cross-efficiency model based on super-efficiency for ranking units through the TOPSIS approach and its extension to the interval case," Mathematical and Computer Modelling, vol. 53, no. 9-10, pp. 1946-1955, 2011.

[33] H. Jahanshahloo, F. H. Lotfi, and M. Khodabakhshi, "Modified nonradial supper efficiency models," Journal of Applied Mathematics, vol. 2014, Article ID 919547, 5 pages, 2014.

[34] M. Khodabakhshi, "An output oriented super-efficiency measure in stochastic data envelopment analysis: considering Iranian electricity distribution companies," Computers and Industrial Engineering, vol. 58, no. 4, pp. 663-671, 2010.

[35] M. Khodabakhshi, "Chance constrained additive input relaxation model in stochastic data envelopment analysis," International Journal of Information \& Systems Sciences, vol. 6, no. 1, pp. 99-112, 2010.

[36] S. Li, G. R. Jahanshahloo, and M. Khodabakhshi, "A superefficiency model for ranking efficient units in data envelopment 
analysis," Applied Mathematics and Computation, vol. 184, no. 2, pp. 638-648, 2007.

[37] A. Payan, F. Hosseinzadeh Lotfi, A. A. Noora, and M. Khodabakhshi, "A modified common set of weights method to complete ranking DMUs," International Journal of Mathematical Models and Methods in Applied Sciences, vol. 5, no. 7, pp. 11431153, 2011.

[38] S. Ramazani-Tarkhorani, M. Khodabakhshi, S. Mehrabian, and F. Nuri-Bahmani, "Ranking decision-making units using common weights in DEA," Applied Mathematical Modelling, 2013. 


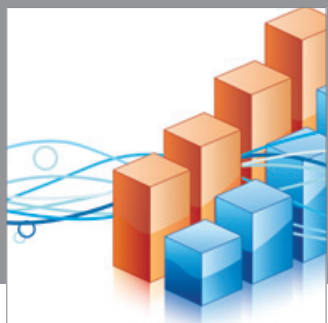

Advances in

Operations Research

mansans

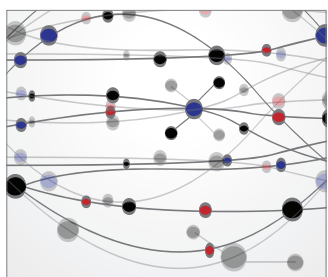

The Scientific World Journal
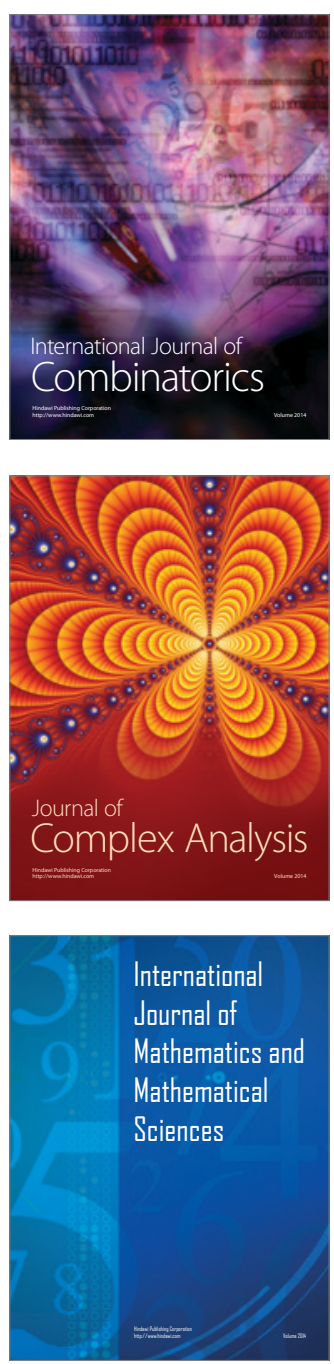
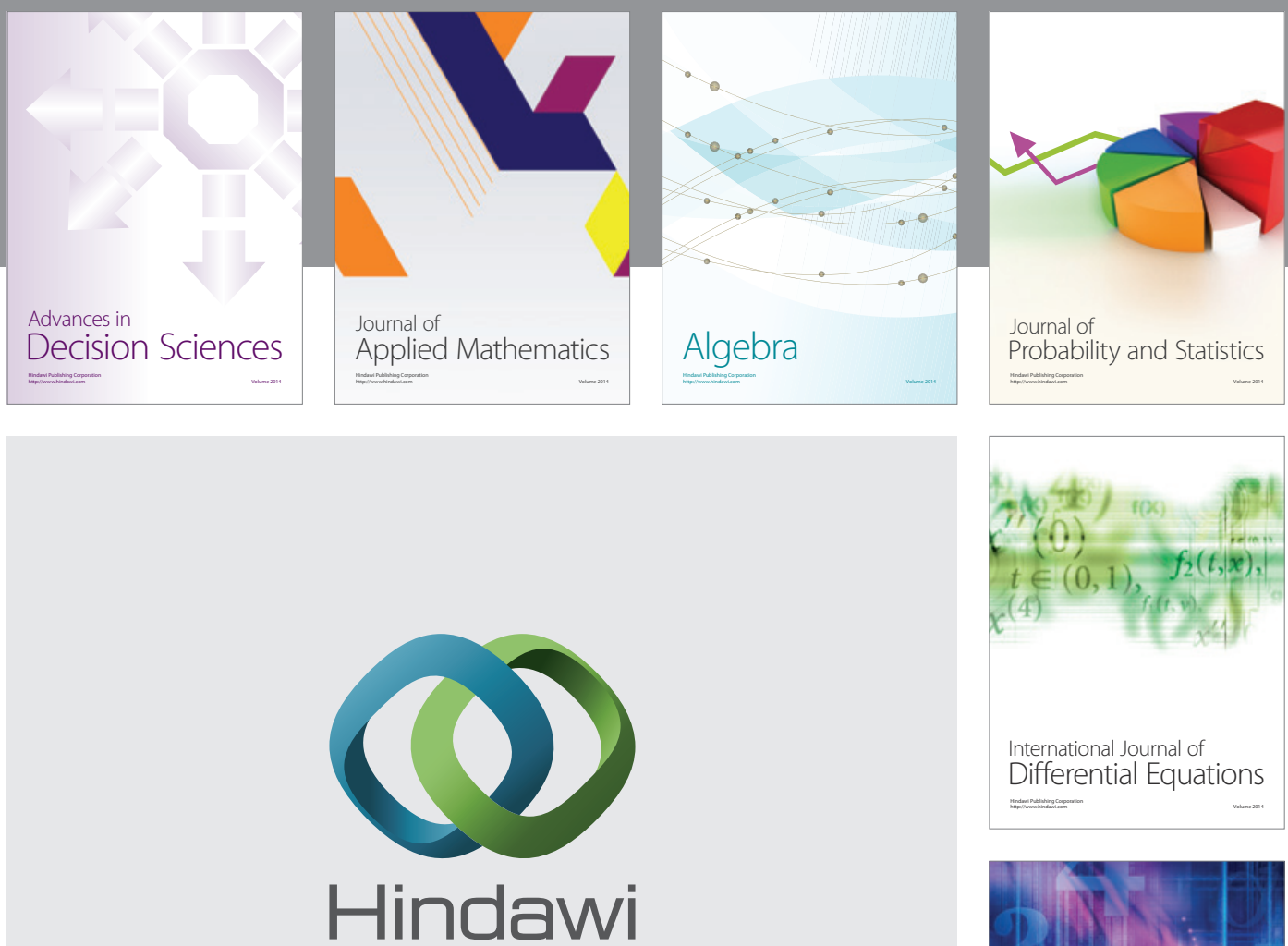

Submit your manuscripts at http://www.hindawi.com
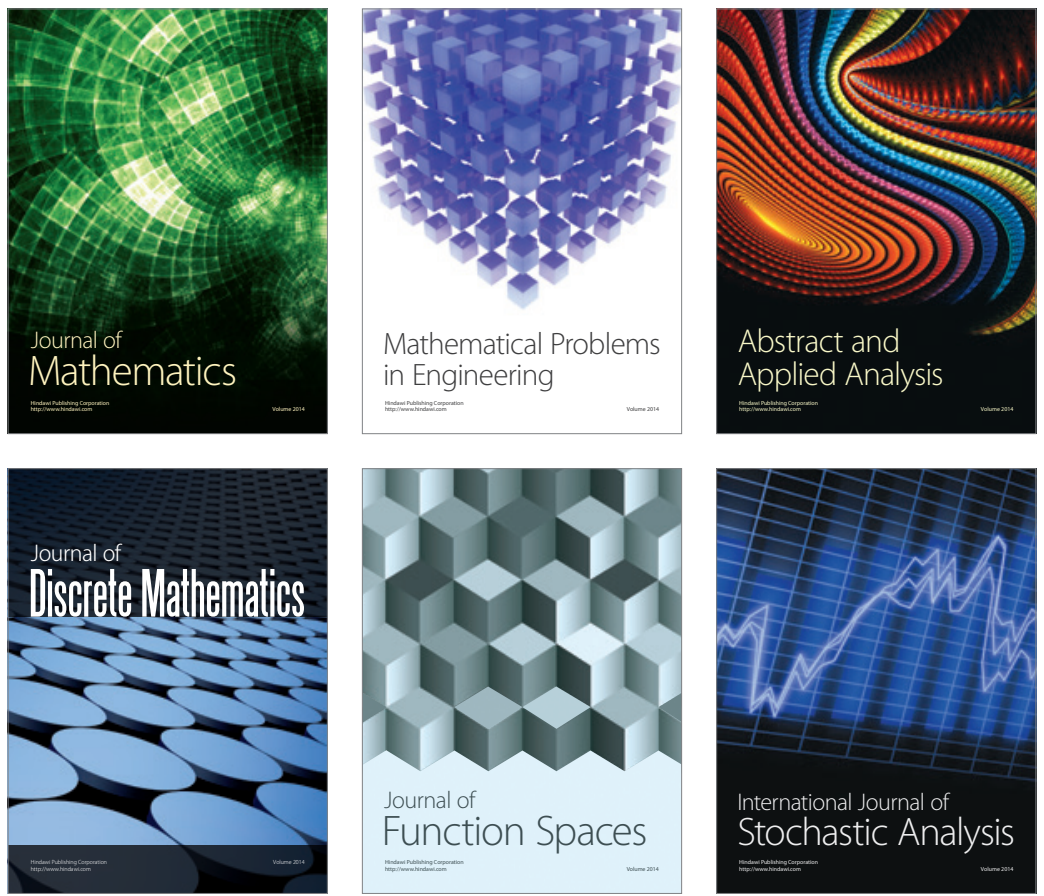

Journal of

Function Spaces

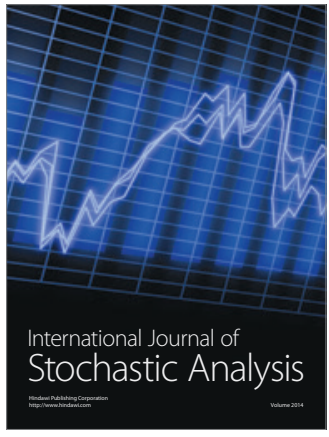

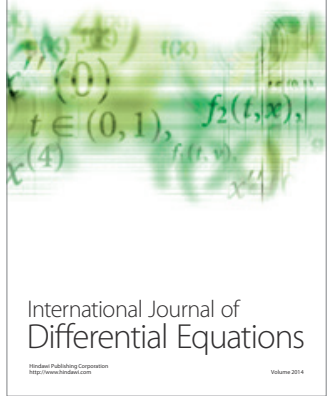
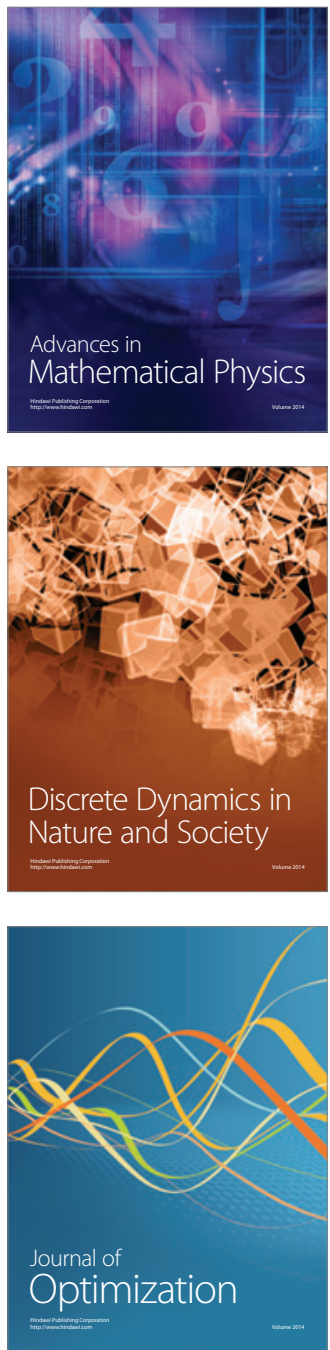